\title{
High Photocatalyst Module on Degradation of Extracted Gas from Soil under Visible Light
}

\author{
Ernso Fenelon ${ }^{1}$, Adnan Hussain ${ }^{2}$, Tsung-Han Yang ${ }^{2}$, Gen-Mu Chang ${ }^{3}$, Shyh-Wei Chen ${ }^{4}$, \\ Ren-Jieh Wei ${ }^{2}$, Sheng-JieYou ${ }^{2}$, Ya-Fen Wang ${ }^{2 *}$ \\ ${ }^{1}$ Department of Civil Engineering, Chung Yuan Christian University, Taoyuan 32023, Taiwan \\ ${ }^{2}$ Department of Environmental Engineering, Chung Yuan Christian University, Taoyuan 32023, Taiwan \\ ${ }^{3}$ Environmental Protection Bureau, Chiayi City Government, Chiayi 60045, Taiwan \\ ${ }^{4}$ Environmental Protection Administration Executive Yuan, Taipei City 10042, Taiwan
}

\begin{abstract}
Photocatalytic oxidation (PCO) is a promising technology for air purification due to low operating cost, potentially long service life, and low maintenance. In order to establish a high efficiency for removal of solid vapor extraction (SVE), in this study activated carbon was used for adsorption of SVE and lanthanum-doped titanium dioxide as a photocatalyst. The photocatalyst was coated on the glass fiber cloth and applied to the photocatalytic module and then performed for degradation of $15 \mathrm{ppm}$ toluene. The adsorption module was used to eliminate the residual contaminants. The X-ray diffraction (XRD), Scanning electron microscopy (SEM) and the diffused reflectance spectroscopy (DRS), showed the synthesis of the catalyst were successfully prepared and the photocatalytic commercial module was designed by four photocatalytic glass fiber cloths under visible light. The adsorption module was designed by five layers of activated carbon each layer contained $30 \mathrm{~g}$ of activated carbon sets in the photocatalytic module. When the ambient humidity is less than $4 \mathrm{RH} \%$, the removal efficiency was overtaken more than $95 \%$ within 1 hour. The experimental results depict that the photocatalytic commercial module is assembled with flow rate less than 3 liters per minute and the removal efficiency can be stable for more than 72 hours.
\end{abstract}

Keywords: Photocatalysis; Soil gas extraction; Titanium dioxide; Toluene; Visible light.

\section{INTRODUCTION}

The indoor air quality is a great concern, especially in public places such as schools, offices, shopping malls. mostly due to tightly sealed buildings for energy conservation and in some case due to poor ventilation. However, most systems do not take into account the concentration of pollutants indoors, which may fluctuate over time ( $\mathrm{Li}$ and Biswas, 2017).

Photocatalyst is a method using light energy with the potential level to provide energy for the chemical reaction (Feng et al., 2019). In recent years, due to the development of science and technology, the condition of human living standards, mostly people have their own cars; people use more and more fuels in transportation. The underground oil tanks and large petrochemical storage tanks of domestic gas stations are old due to pipelines loose or ground subsidence causing leakage of stored material in the tank and lead to the

\footnotetext{
* Corresponding author.

Tel.: 03-265-4912

E-mail address: yfwang@cycu.edu.tw
}

soil and groundwater becomes polluted. Some preview studies found that the most common pollutants in soil and groundwater contaminated by oil are total petroleum hydrocarbons (TPH), Benzene, Toluene, Xylenes, Ethylbenzene, phenol (Irie et al., 2003) and other volatile organic carbons(VOC's) that cause to damage central nervous system (Lerner et al., 2012; Hua et al., 2018; Juuti et al., 2019) of human body as well as environmental degradation. Additionally, Industries, commercial facilities, public institutions, residential households, extraction and refining of fossil fuels and biomass burning are the sources of VOCs (Ou-Yang et al., 2017; Widiana et al., 2017; Alvim et al., 2018; Hu et al., 2018). Nonetheless, a comprehensive global assessment of the nature and concentration of VOC emissions associated with rendering operations has never been undertaken (Guerra et al., 2017). VOCs are a comprehensive term for numerous organic compounds with sufficiently low boiling points and thus high volatility (Ishikawa et al., 2018; Wang et al., 2018). Because of the complexity and uniqueness of the furniture industry as well as differences in emission control technologies between enterprises, no single emission factor can effectively measure VOCs emissions (Cheng et al., 2018).

In order to remove volatile organic compounds (VOCs) 
from soil or groundwater, the common domestic remediation technology is Solid Vapor Extraction (SVE) (Yu et al., 2019). The principle is to use vacuum pumping continuously through the pump well to generate the negative pressure from the polluted soil (Rathfelder et al., 1995) causing by the pollutants stored in the soil and transfer the contaminants from the solid or liquid phase to the gas phase, the pollutants could be extracted in the direction of the pump well with different pressure to extract the gas in the soil. Finally, the gas in the soil can be removed and discharged after the treatment.

In order to comply the regulations, most of the domestic application used under activated carbon towers to treat the pollutants. Therefore, this study was intended to develop a commercial module that can be directly connected to exhaust the SVE method by using lanthanum-doped titanium dioxide and a small amount of activated carbon.

Although titanium dioxide has a high photocatalytic activity, however it can only react under ultraviolet light. Many scholars are committed to improve the photocatalytic activity of titanium dioxide under visible light to solve the problem of environmental pollution for saving energy and improve the efficiency. The results show through the metal (Eshaghi and Moradi, 2018; Gao et al., 2019; Matos et al., 2019; Qiu et al., 2019) non-metal (Hoseini et al., 2017; Barmeh et al., 2018; Ho et al., 2019; Shafei and Sheibani, 2019; Tbessi et al., 2019) and rare earth elements (Chiou and Juang, 2007; Yajun et al., 2011; Shao et al., 2018; Thiruppathi et al., 2018; Singh et al., 2019) doped with titanium dioxide can effectively improve the degradation efficiency of titanium dioxide on pollutants.

In this study, lanthanum element was mixed into the commercial titanium dioxide and preparing lanthanum-doped titanium dioxide coating by a sol-gel method to reduce the band gap of catalyst to improve the photocatalytic activities of the material under visible light. Additionally La-doped $\mathrm{TiO}_{2}$ can promote electron-hole separation, as $\mathrm{La}^{3+}$ can have synergistic effects and capture photoinduced electrons (Huang et al., 2017). Furthermore, the photocatalyst was coated on the glass fiber cloth and applied to the photocatalytic module. Finally, the adsorption process of the residual exhaust gas was performed through the adsorption module. In this paper the photocatalytic commercial module was assembled by adsorption module and photocatalytic module which is used to reduce toluene as hazardous gas present in the soil through soil vapor extraction (SVE) process for the treatment of soil gases. Finally, the processing of the performance of the photocatalytic commercial module was tested in the real site.

\section{EXPERIMENTAL}

\section{Materials}

The following chemicals used in this study were analytical graded (Huang et al., 2017). No need to be purified and it can used directly, all dilutions were treated with deionized water prepared by Lab Water Purification Systems (ELGA Lab Water, UK). The following chemicals are used: Tetrabutyl titanate (TBOT) from Alfa Aesar, Anhydrous ethanol from Japan (99.5\%), Nitric acid from Panreac
AppliChem, Lanthanum nitrate from FERAK, Toluene standard gas from Ming yang Special Gas Company.

\section{Preparation of Glass Fiber Cloth Coated with Lanthanum- doped Titanium Dioxide ( $\mathrm{La}^{-\mathrm{TiO}_{2}}$ )}

The preparation method of $\mathrm{La}^{-\mathrm{TiO}_{2}}$ refers to the method of (Hoseini et al., 2017). First, $50 \mathrm{ml}$ of ethanol and $10 \mathrm{~mL}$ of tetrabutyl titanate were thoroughly stirred at $400 \mathrm{rpm}$ for 10 minutes. This was the reaction of precursor; Next $5 \mathrm{M}$ of $4.5 \mathrm{~mL}$ nitric acid solution was slowly added to $4.5 \mathrm{~mL}$ of deionized water and dissolved in $1.864 \mathrm{~g}$ of lanthanum $(1 \%$ by weight). This solution was a reaction of catalyst; the reaction of catalyst was slowly added dropwise to the reaction of precursor and stirred at $800 \mathrm{rpm}$ for 10 minutes. Furthermore, the paraffin film was sealed, and the speed was adjusted to $400 \mathrm{rpm}$ and stirred for 2 hours. Afterward the gel solution was placed in the oven at $60^{\circ} \mathrm{C}$ for 12 hours and then the gel was removed then placed under room temperature. For the preparation of glass fiber cloth coated, the sol-gel was poured into a vessel and then the glass fiber cloth was immersed in the solution to uniformly coat by the lanthanumdoped titanium dioxide. After drying, it was placed in a furnace at $400^{\circ} \mathrm{C}$ for 2 hours to obtain a photocatalytic glass fiber cloth.

\section{Photocatalytic Module Developments}

In this study, the design of the photocatalytic module was assembled and showed in Fig. 1, the module was a cylindrical reactor tank with an internal diameter of $19 \mathrm{~cm}$, and the internal capacity was $6785.84 \mathrm{~mL}$. There are 5 lamps holders inside the module adjusted in different position; in the front, back, left, right and in the middle of the module respectively. In the surrounding part of the middle lamp had a tube frame, reaction with a chamber where the polluted gas was passed. The chamber also placed for reaction of photocatalytic glass fiber cloth. The average coating amount of each glass fiber cloth is $80.62 \mathrm{~mL}$ of lathanium-doped on titanium dioxide sol. In this study, different environmental humidity and photocatalytic glass fiber was placed into the module test.

\section{Adsorption Module Development}

The specification of the adsorption module in Fig. 2, the overall specification of the adsorption module is an acrylic module of length of $22 \mathrm{~cm}$, a width of $21 \mathrm{~cm}$ and a height of $23.5 \mathrm{~cm}$. At the end of the bottom side, a stand length of $2 \mathrm{~cm}$, width of $2 \mathrm{~cm}$ and height of $10 \mathrm{~cm}$ is arranged, and the upper part of the module the diameter of air inlet hole is $1 / 4$ inch. Below, there is a venting hole of $1 / 4$-inch of diameter and a diverging flow channel was arranged above and below the module to facilitate a rapid diffusion of the polluted gas. The upper part was provided with a rectifying plate, and the internal specification of the rectifying plate was $14 \times$ 12 holes with a radius of $0.2 \mathrm{~cm}$ and in order to avoid the escape of internal contaminants during the usage of module, each internal component is provided with 8 holes for screws (M3) and a resin is applied to the inner surface.

The internal carrier specifications of the rectifying plate adsorption module are shown in Fig. 3. The overall specification of the carrier is an acrylic module with a length 


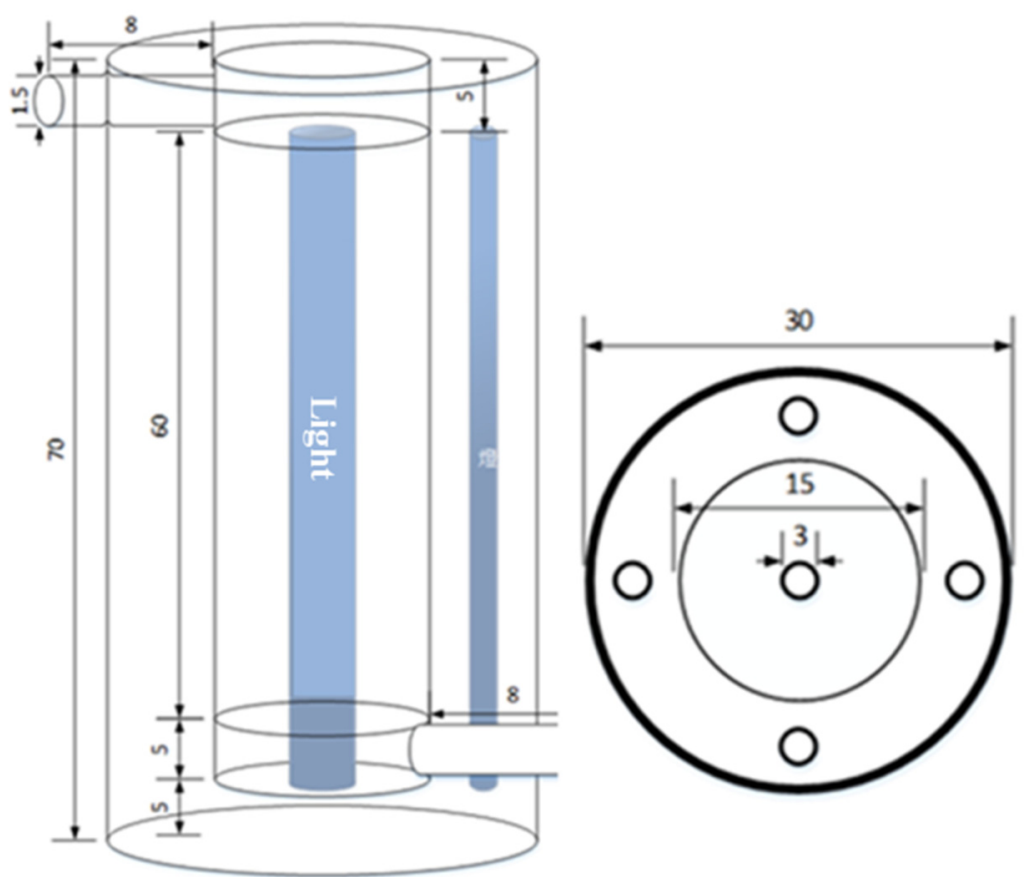

Fig. 1. Photocatalytic module.

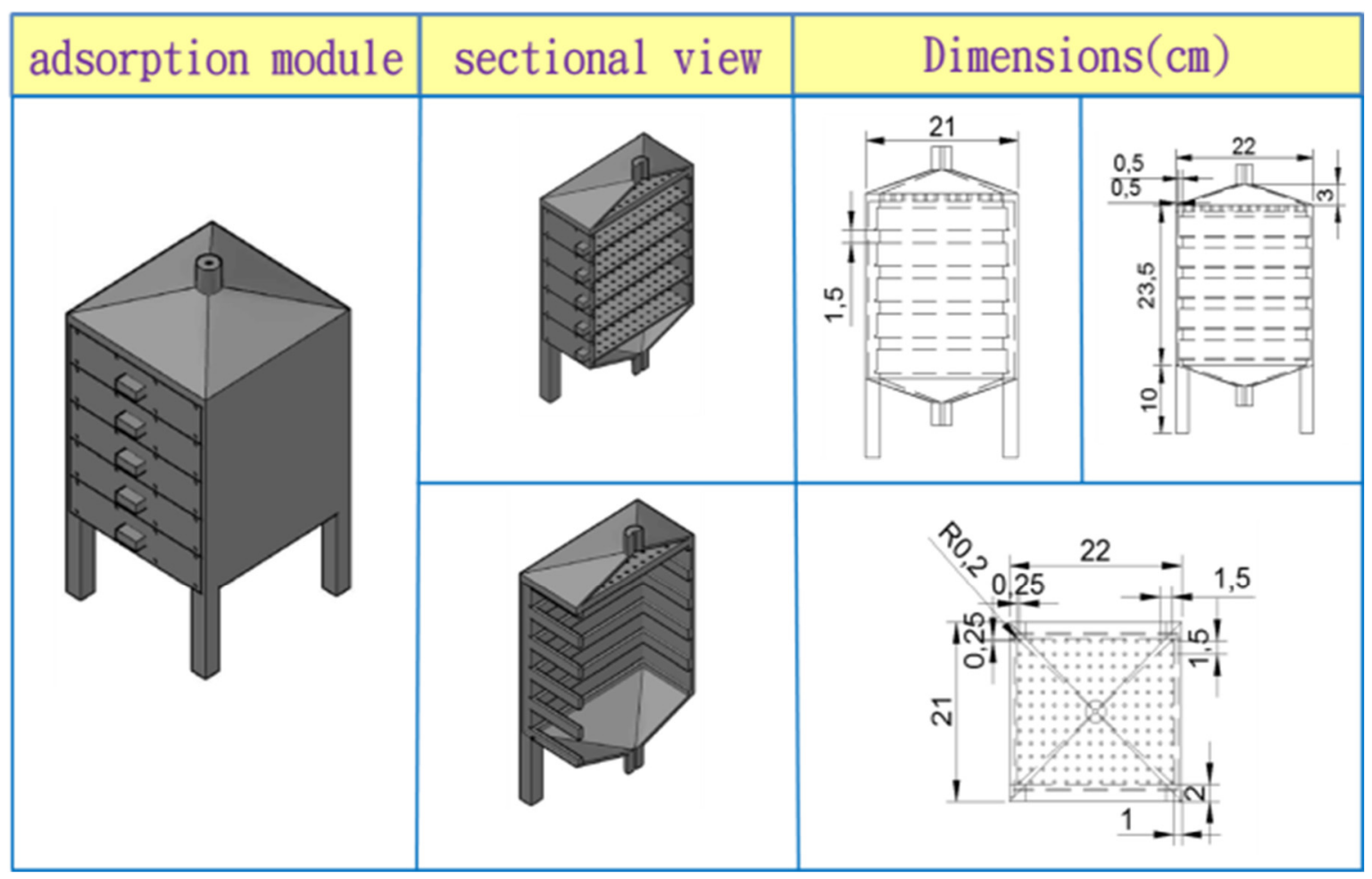

Fig. 2. Adsorption module body design.

of $20 \mathrm{~cm}$, a width of $16.5 \mathrm{~cm}$ and a height of $3 \mathrm{~cm}$, and a rectifying plate is arranged at the bottom. The internal specification of the rectifier plate is 1412 holes with a radius of $0.2 \mathrm{~cm}$.

This study tested the optimal parameters of the adsorption module by testing the number of layers in the carrier, the amount of activated carbon and the flow of pollutants. Each experiment was tested by uniformly spreading the activated carbon on the carrier.

\section{Experimental Mode Field Design}

The equipment's test which was used is shown in Fig. 4. The pipeline used in the system was connected to $1 / 4$ diameter of Teflon tube. First, the toluene standard gas in 


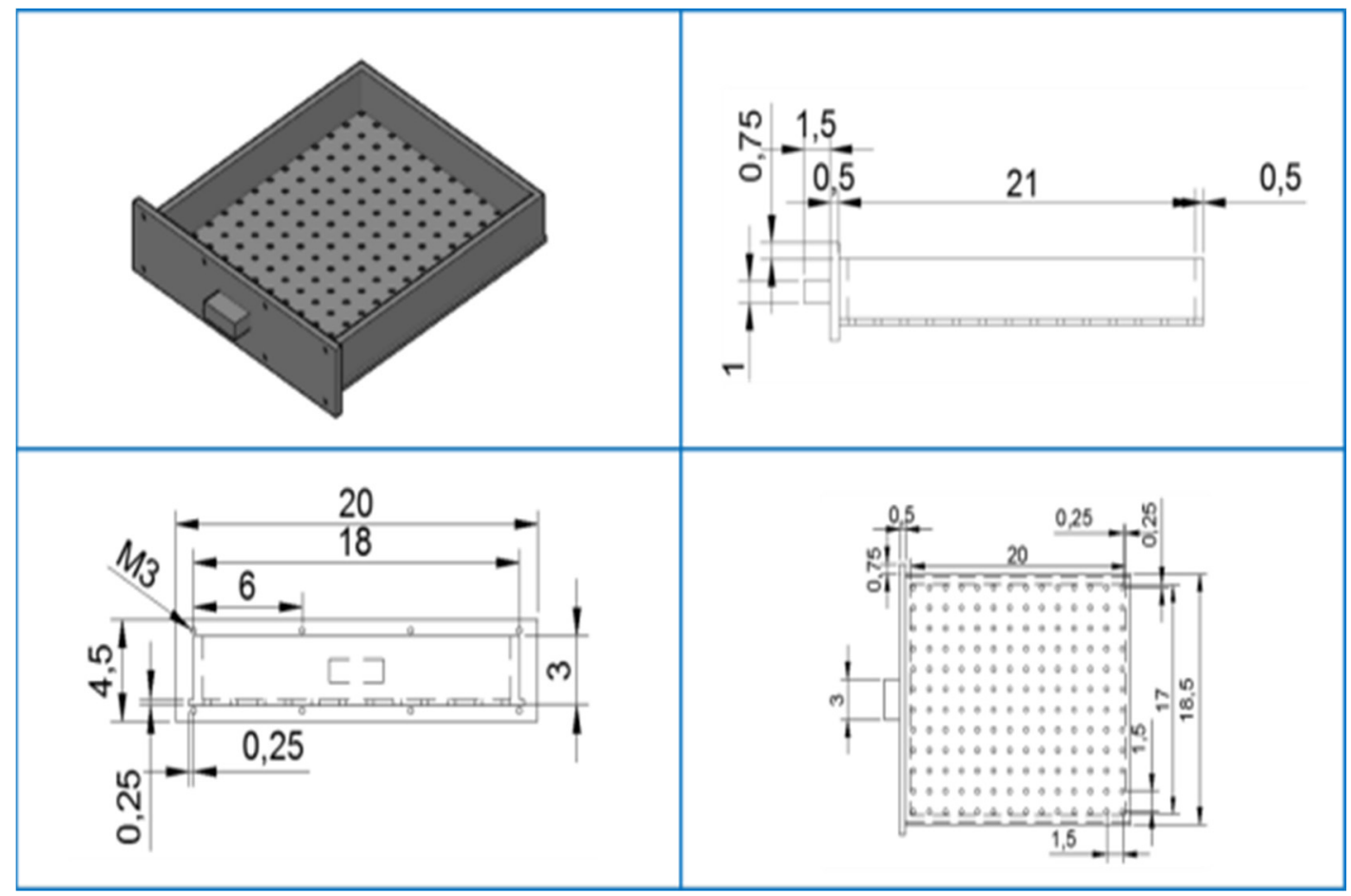

Fig. 3. Adsorption module carrier design.

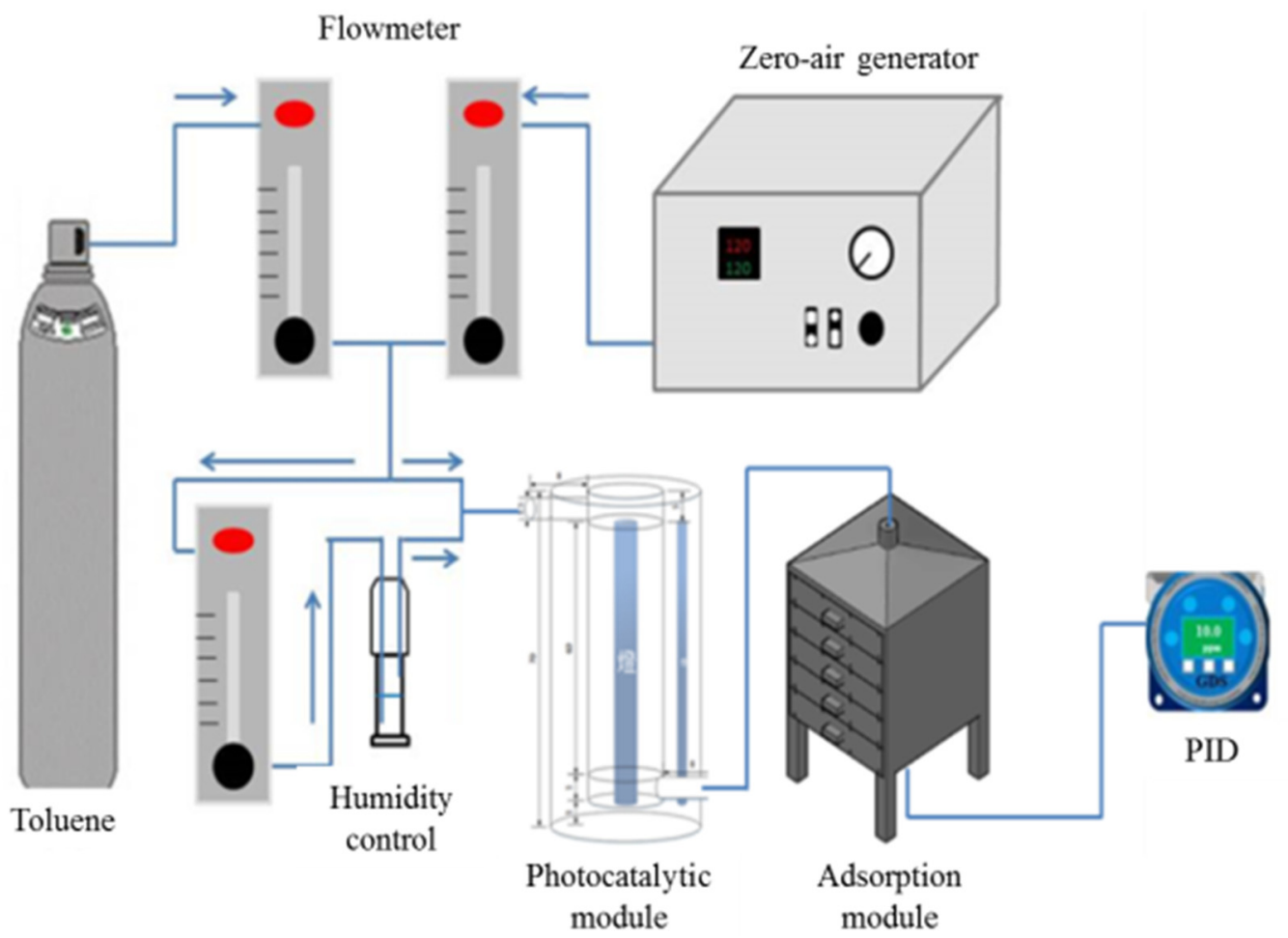

Fig. 4. Laboratory model field design.

the cylinder was treated by zero-value gas generators at high temperature and through to two floats flow meters. Then the mixed gas was used to regulate the relative humidity through another float flow meter. The contaminants are tested through pre-test modules. Finally, the photoionization detector (PID) device was used to calculate the pollutant removal rate.

\section{RESULTS AND DISCUSSION}

\section{SEM Result}

The SEM result showed in the Figs. 5(a) and 5(b) the photocatalyt coated on glass fiber. It was shown that the surface of the catalyst was smooth and has low impurities. It 

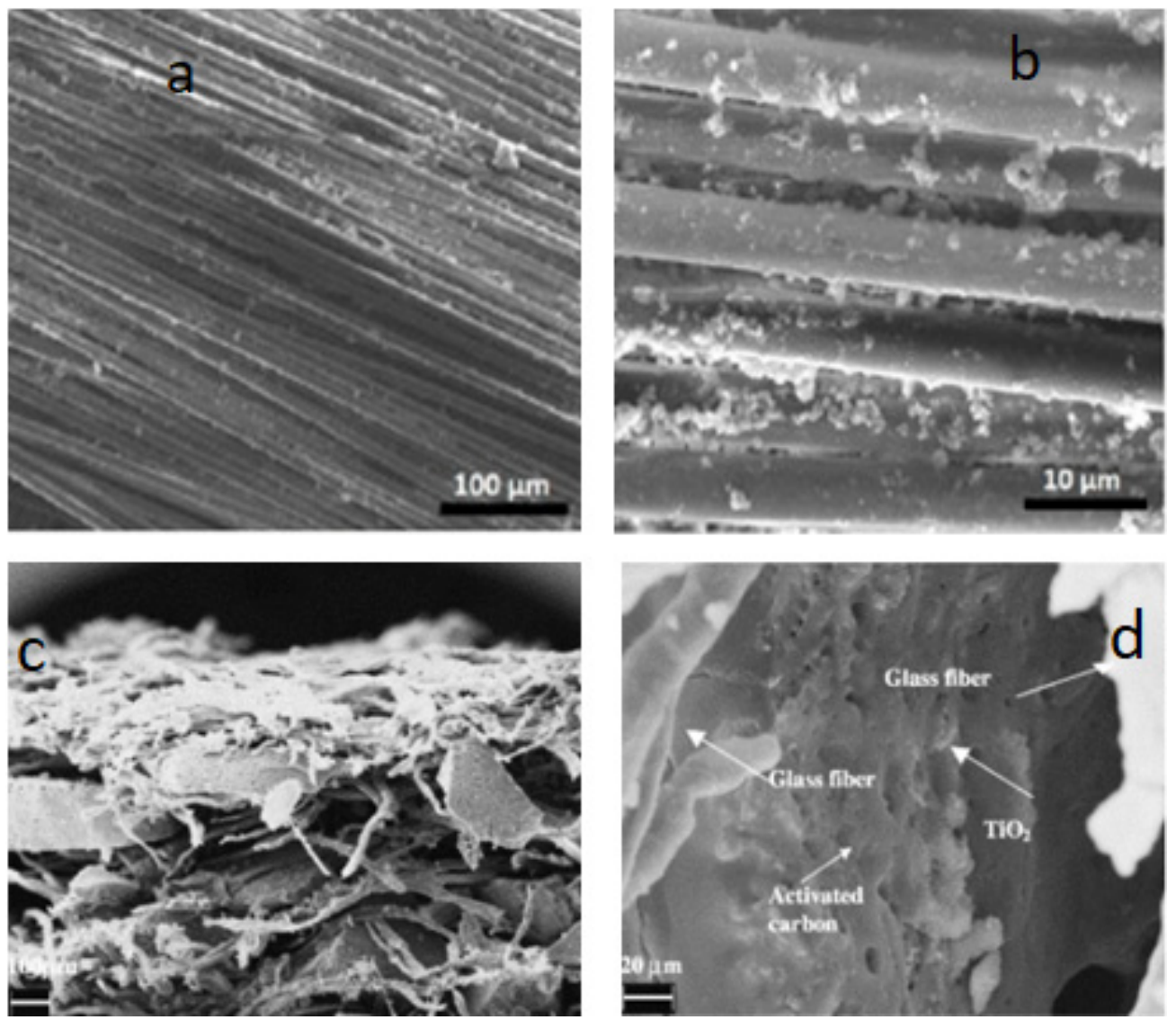

Fig. 5. (a, b) Photocatalyst coated on glass fiber and (c, d) Photocatalyst coated by activated carbon.

was shown that the surface of the material was covered with catalyst, but the catalyst had large particle size, uneven dispersion and agglomeration, and the binding was not high, and the load was small in the Figs. 5(c) and 5(d) the photocatalyst coated by activated carbon. The result has been proved that the presence of all material in the composite and clear recognize that the activated carbon coted on the photocatalyst showed the best surface area, higher pore size, smoother and more regular. This may be an explanation as to why the photocatalytic modules work very well on photodegradation of toluene.

\section{XRD Analysis Results}

The Fig. 6 shows the XRD analysis of lanthanum-doped titanium dioxide. Titanium dioxide reference JCPDS Card no. 21-1272, which can be seen at $2 \theta$ angles (27.0, 35.6, $40.8,54.0,53.9,56.1$ and 61.0 , corresponding to (110), (101), (200), (111), The crystal faces of (210), (211), (220), (002) and (310), and the rutile reference JCPDS Card no. 65-0191 and it can be seen that there are many changes in the crystal form of the doped titanium dioxide. In addition, $1 \%$ of lanthanum-doped titanium dioxide can show that its crystal form peaks are all based on pure titanium dioxide, from which it could be inferred that the anatase crystal form was still intacted, until the doping amount of $3 \%$ or more shows that the crystal form of the titanium has been destroyed. The crystal form of the anatase of titanium dioxide is also analyzed from the Search-Match of the XRD

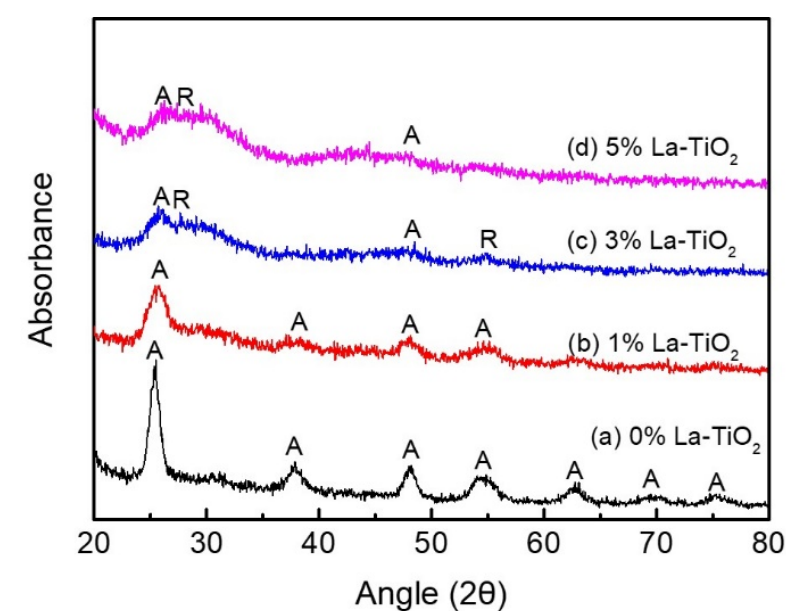

Fig. 6. The XRD pattern of Lanthanum doped on titanium dioxide.

analysis software in Figs. 4.5.1-2, and compared with the pdf No. 84-1286 of the XRD library. It can be seen that the undoped titanium dioxide crystal form is relatively complete, and the peaks of various anatase crystal forms in the library are all feedback to the anatase crystal form of this study.

It can be inferred that the experimental method has the ability to effectively produce titanium dioxide which can be used, and the $1 \%$ cerium-doped titanium dioxide can still reproduce the crystal form peak of anatase. 


\section{DRS Analysis Results}

Ultraviolet-visible diffuse reflectance absorption spectroscopy analysis of different doping amounts of titanium dioxide, ultraviolet light-visible interval electromagnetic wave continuous spectrum as a light source to illuminate the sample, to study the relative strength of the molecule of material for spectral absorption and by observation spectrum to analyze the light absorption range of the sample and qualitatively analyze the material.

$(\alpha h v)^{1 / n}=A\left(h v-E_{g}\right)$

Two ways to obtain the semiconductor energy gap width from the UV-Vis DRS spectrum are the intercept method; the other one that appears more often is the Tauc polt method from the Tauc polt method, mainly based on Tauc, Davis and Mott et al. The proposed formula, commonly known as Tauc plot. The unit of the formula is as follows: $\alpha$ is the absorbance value, $\mathrm{h}$ is the planck constant, $\mathrm{v}$ is the frequency, $\mathrm{A}$ is a constant, and $\mathrm{Eg}$ is the semiconductor forbidden band width. The index $\mathrm{n}$ is directly related to the semiconductor type: direct bandgap semiconductor: $n=1 / 2$; indirect bandgap semiconductor: $\mathrm{n}=2$. After $(\alpha \mathrm{hv}) 1 / \mathrm{n}$ is plotted for $\mathrm{hv}$, the measurement map of the forbidden band width can be obtained, and then the change of the forbidden band width can be estimated.

And through the literature, the erbium-doped photocatalyst is an indirect bandgap semiconductor, so the formula is (ahv) $1 / 2=\mathrm{A}\left(\mathrm{hv}-\mathrm{E}_{\mathrm{g}}\right.$ ), and the data of the ultraviolet-visible diffuse reflection absorption spectrum is used as a reference, and then the conversion was calculated. For the data of the forbidden band width, and draw the two as a graph to observe the change in light absorption capacity.

The Fig. 7 shows the UV-visible diffuse reflectance absorption analysis of different doping amounts of titanium dioxide. The doping of titanium dioxide causes changes in the absorption range of the sample. The huge absorption may come from the energy required for the valence band of the titanium dioxide to be excited to the conduction band, and it was speculated that the undoped titanium dioxide is in the ultraviolet, so the light interval has a good absorption characteristics.

In the Fig. 8 the band width of different doping amounts of titanium dioxide can be understood. Auxiliary observation of the change of the band width, the band width of undoped titanium dioxide is $3.06 \mathrm{eV}$; however, $1 \mathrm{wt} \% \mathrm{La}-\mathrm{TiO}_{2}$ the band width is $2.57 \mathrm{eV}, 3 \mathrm{wt} \% \mathrm{La}-\mathrm{TiO}_{2}$ the band width is $2.3 \mathrm{eV}, 5 \mathrm{wt} \% \mathrm{La}^{-\mathrm{TiO}_{2}}$ has a band width of $1.85 \mathrm{eV}$. According to the change of the band width, the lower of band gap has the higher the redshift degree, so that a doped photocatalyst can be obtained. It is able to change its light absorption capacity and cause a red-shifting effect. Its doping can make the nano-particle size of the sample smaller, and the photocatalytic reaction could be led from the original ultraviolet-absorbing region to the absorption-visible region.

\section{Photocatalyst Humidity Test}

The effect of different ambient humidity on the removal of toluene efficiency from 1 wt. $\% \mathrm{La}^{-} \mathrm{TiO}_{2}$ is shown in

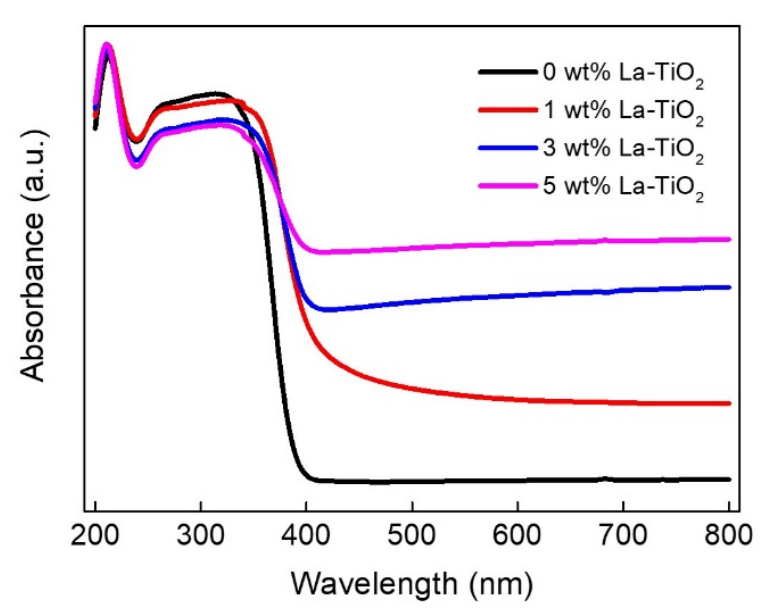

Fig. 7. UV-visible diffuse reflectance absorption analysis of different doping amounts on titanium dioxide.

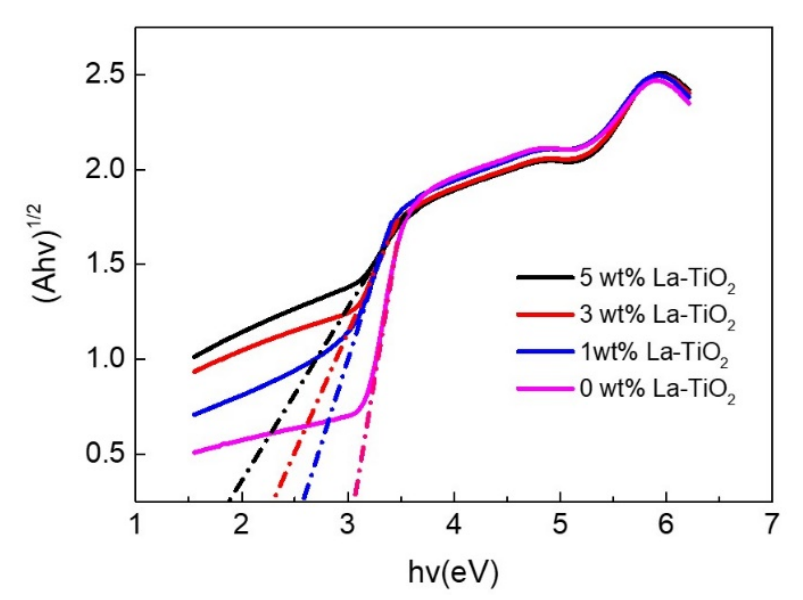

Fig. 8. Different doping amount of titanium dioxide band width.

Fig. 9. The experimental results confirmed that the increasing of humidity (Kawar and Underhill, 1999) have impact on the degradation efficiency of Toluene using lanthanum-doped titanium dioxide. When the ambient humidity is greater than $4 \mathrm{RH} \%$ the maximum instantaneous degradation efficiency reached $24 \%$ if the ambient humidity was $60 \mathrm{RH} \%$ and $80 \mathrm{RH} \%$ the maximum instantaneous degradation efficiency reached $23.21 \%$ and $18.18 \%$ respectively. This phenomenon occurs because the photocatalyst was irradiated with light to obtain energy greater than the forbidden band width. Inducing electrons on the photocatalyst cause the transition of electrons from the valence band to the conduction band. The superoxide radicals $\left({ }^{\bullet} \mathrm{O}^{2-}\right)$ and hydroxyl radicals $\left({ }^{\bullet} \mathrm{OH}\right)$ are generated by the action of the generated electrons and holes transferred to the surface of the photocatalyst. Therefore, increasing the ambient humidity can also increase the production of superoxide radicals $\left({ }^{\circ} \mathrm{O}^{2-}\right)$ and hydroxyl radicals $\left({ }^{\circ} \mathrm{OH}\right)$. Adding a certain proportion of the environmental humidity of the pollutants increased the removal efficiency of the photocatalyst to the pollutants. However, if the ambient humidity is high, large amount of water molecules are attached to the surface of the photocatalyst. 
There is less chance of contact between photocatalyst and the contaminant, as a result generally the removal efficiency is reduced (Thiruppathi et al., 2018).

\section{Photocatalytic Module Testing}

The comparison of the removal efficiency of toluene in a photocatalytic module using different amounts of photocatalytic glass fibers under visible light is shown in Fig. 10. The experimental result shows that the photocatalytic module was consisted of 4 pieces of photocatalytic glass fiber cloth $(1,2,3,4)$ respectively, the removal efficiency of 4 th piece was reached $66.9 \%$ which is the best removal efficiency as compared to other pieces.

\section{Adsorption Module Construction}

In order to avoid the short-flow phenomenon inside of adsorption module, using ANSYS finite element analysis software to analyze the internal flow field of the module. The analytical model setup in this study was the internal fluid model of 1/4 adsorption module the model boundary conditions for the inflow velocity, the outflow velocity, Symmetric all surfaces and unchangeable walls were set, the intake air flow rate was calculated by the following formula the fluid parameters use the toluene gas parameters of the ANSYS assembled-in database.

Inlet velocity $=\frac{\text { flow }}{\text { inlet area }}=1.58\left(\mathrm{~m} \mathrm{~s}^{-1}\right)$

The flow field analysis results of the adsorption module are shown in Fig. 11. The analysis results were shows that

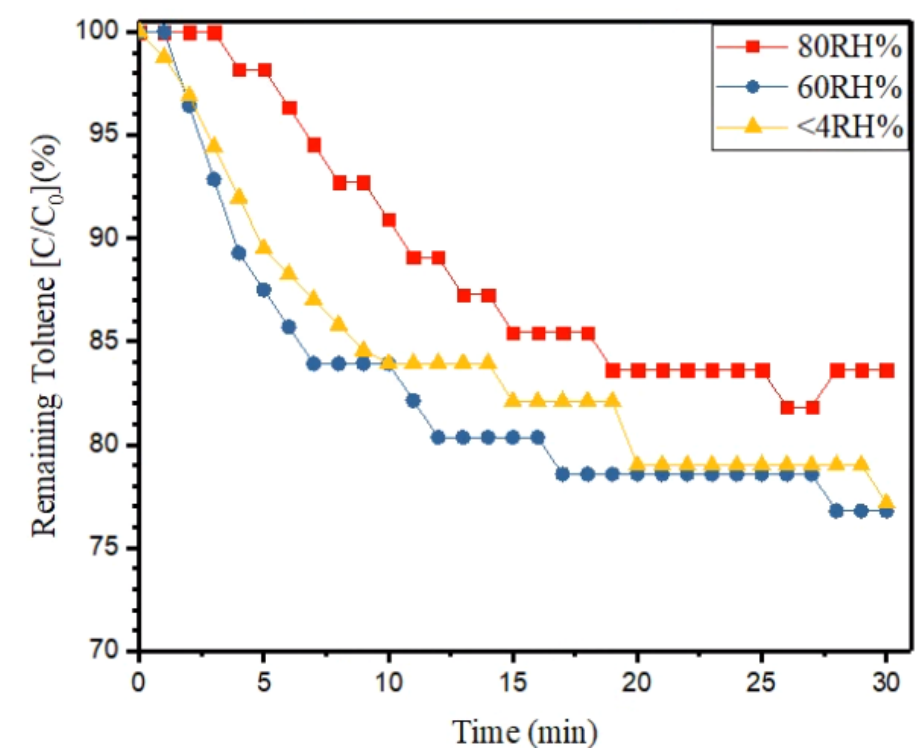

Fig. 9. Effect of different environmental humidity on the removal of toluene by 1 wt. $\% \mathrm{La}^{-\mathrm{TiO}_{2}}$.

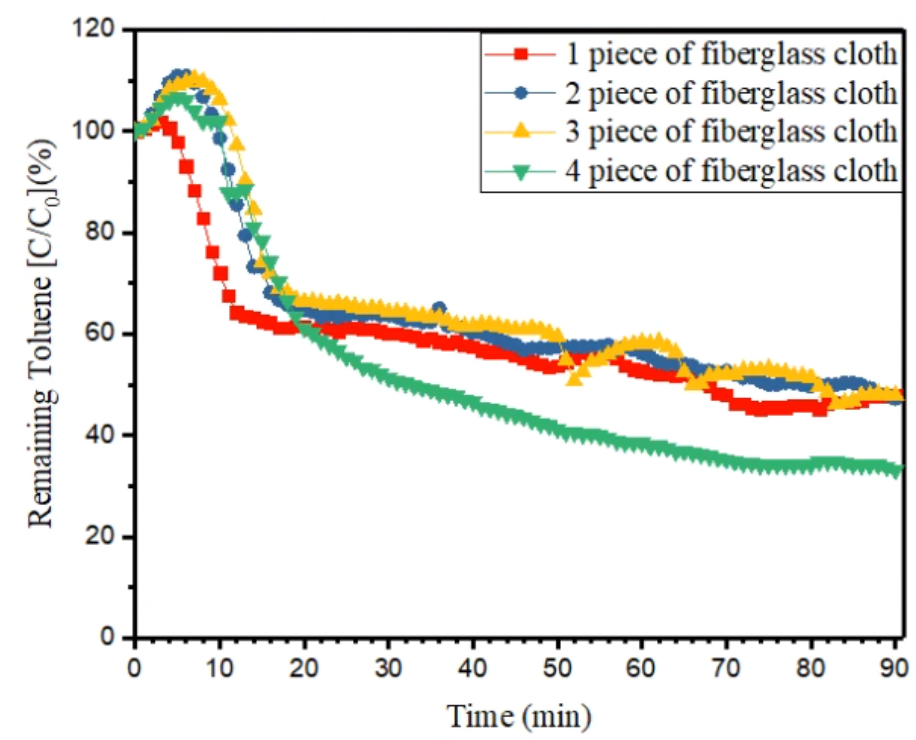

Fig. 10. Effect of the number of photocatalytic glass fiber arrangements on the removal efficiency of toluene. 


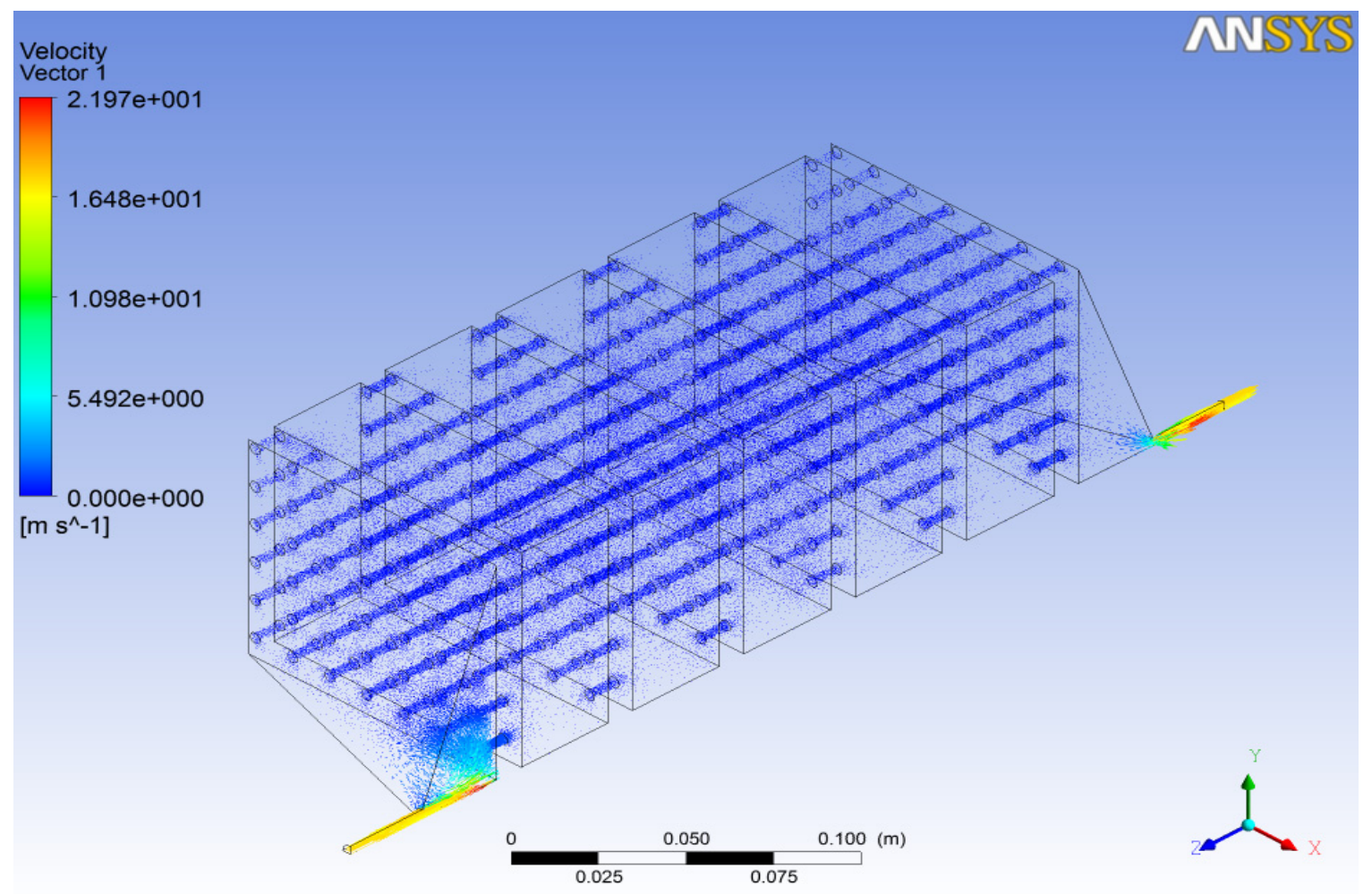

Fig. 11. Internal fluid analysis of the adsorption module.

due to the design of the rectifier plate inside the adsorption module, inside solid adsorption module have almost no short-flow phenomenon. After the polluted gas enters to the adsorption module, first it rectified through the first layer of the rectifying plate and fixed to the body of the module. Therefore, the pollute gas pass through each of small hole in the rectifying plate respectively, and the rectifying plate simultaneously disperse the pollutant. The rectifying plate can simultaneously disperse the flow rate of the polluted gas intake, and when the fluid of flow rate was slow, the occurrence of the short stream was also reduced. This design effectively reduced the short-flow phenomenon that may occur inside the adsorption module

\section{Effect of the Number of Carriers on the Degradation Concentration of Toluene}

The analysis of the effect of different carrier numbers of activated carbon was placed an average weight of $60 \mathrm{~g}$ on different numbers of carriers and spreading it across different numbers of carriers, further testing whether the number of carriers was affected the removal efficiency of the adsorption module. The experimental results are shown in Fig. 12, the best effect carrier layer was 3rd-layer carrier, and where in each layer carrier uses an activated carbon amount of $20 \mathrm{~g} /$ layer. The adsorption effect on toluene reached around $92.4 \%$. The lowest adsorption effect was detected by using 1st-layer which has an adsorption effect on toluene was $84.7 \%$, although it can be covered with activated carbon using only one layer of carrier. However, the experimental results show that high amount of activated carbon may cause poor internal rectification. Therefore, the

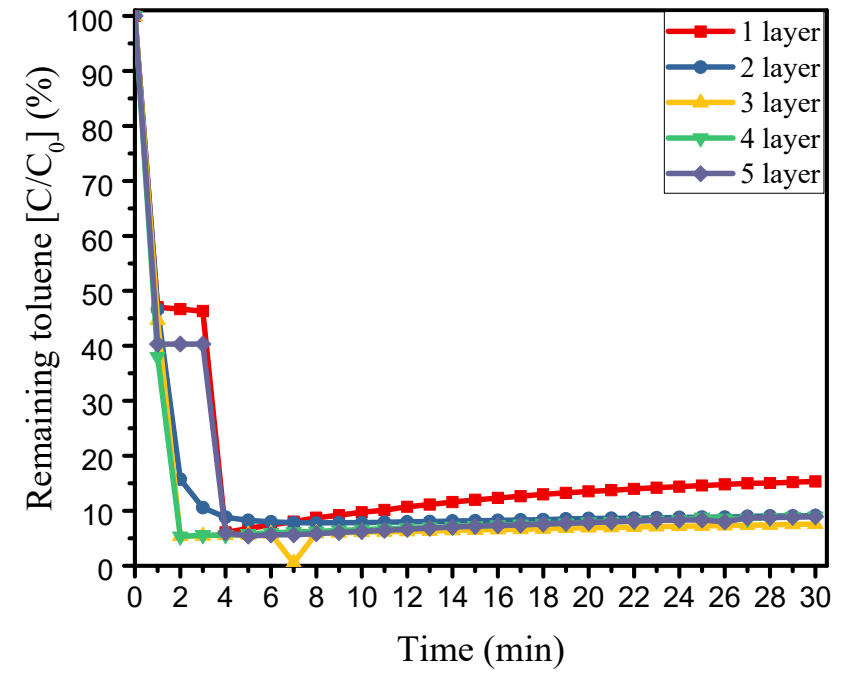

Fig. 12. Effect of the number of carriers on the degradation concentration of toluene.

overall adsorption effect was low, the adsorption effect was reduced and the contaminant was not completely in contact with the activated carbon by using a low amount of activated carbon. Additionally, by using more layers, the amount of activated carbon become higher, the photocatalytic activity of the modules was affected when the activated carbon was higher than the optimum. However, the optimum amount of layers is 2 or 3 , so the removal efficiency decrease by increasing the layers more than 3 , because the amount of activated carbon increases by increasing the layers. 


\section{Effect of Amounts of Activated Carbon in a Single Layer Carrier Test}

As the experimental results in Fig. 13, placing different weights of activated carbon on a 1st-layer of carrier to confirm whether the amount of activated carbon was added to the adsorption module removal efficiency. The best degradation rate was found at $30 \mathrm{~g}$ of activated carbon in a single-layer carrier, the effect of toluene removal was reached at $92.6 \%$, while the other degradation rates were found at 60 $\mathrm{g}, 50 \mathrm{~g}, 40 \mathrm{~g}$ and $20 \mathrm{~g}$ of activated carbon in a single-layer carrier, the effect of toluene removal were reached $84.7 \%$, $85.1 \%, 90.2 \%$ and $85.2 \%$ respectively. According to this result it was concluded that $60 \mathrm{~g}$ of activated carbon in a single-layer carrier has the lowest efficiency rate due to the excessive amount of activated carbon on rectifying plate as compare to other amount of activated carbons. Therefore, an appropriate amount of activated carbon can only increase the removal efficiency of the adsorption module.

\section{Effect of Different Flow Rate of the Pollutant}

The flow rate of the pollutant was affected the removal of the overall adsorption module per unit time. Therefore, the flow rate is an important parameter in the adsorption module. By testing the flow of pollutants, the maximum amount of pollutant that can be removed by the adsorption module per unit time. The comparisons of the removal efficiency of the adsorption module in different flows rate of pollutant are shown in Fig. 14. According to the experimental results, the adsorption module shows that the removal efficiencies were not significant when the flows rate were $1 \mathrm{~L} \mathrm{~min}^{-1}, 2 \mathrm{~L} \mathrm{~min}^{-1}$ and $3 \mathrm{~L} \mathrm{~min}^{-1}$. The removal effect was reached to $92.6 \%$, 93.3\% and $93.5 \%$ for $1 \mathrm{~L} \mathrm{~min}^{-1}, 2 \mathrm{~L} \mathrm{~min}^{-1}$ and $3 \mathrm{~L} \mathrm{~min}^{-1}$, respectively. So, after the overall evaluation, the adsorption module using the flow rate of $3 \mathrm{~L} \mathrm{~min}^{-1}$ as the best parameter.

\section{Photocatalytic Commercial Module Testing}

The photocatalytic reaction mechanism was irradiated by visible light. To obtain the greater energy than the band width; thereby the electrons of the photocatalyst were shifted from the valence band to the conduction band. The superoxide

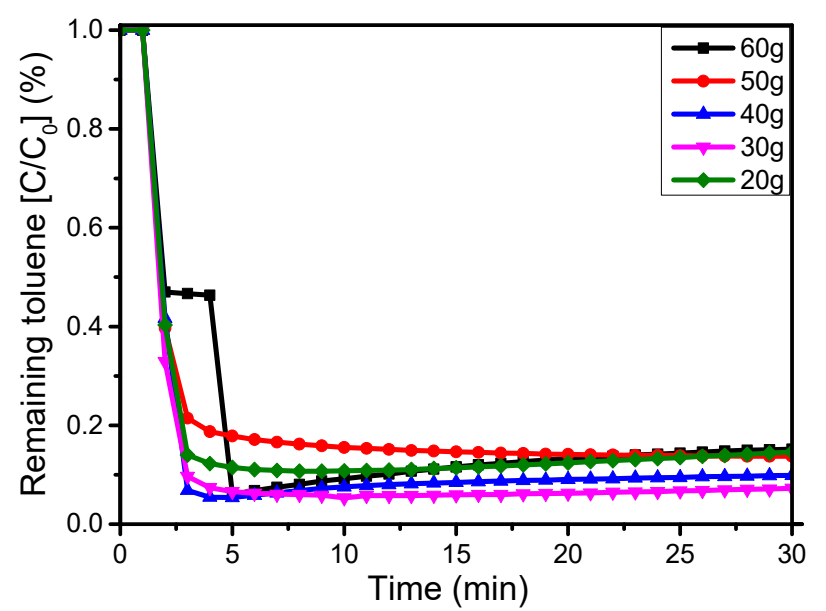

Fig. 13. Different amounts of activated carbon in a single layer carrier test.

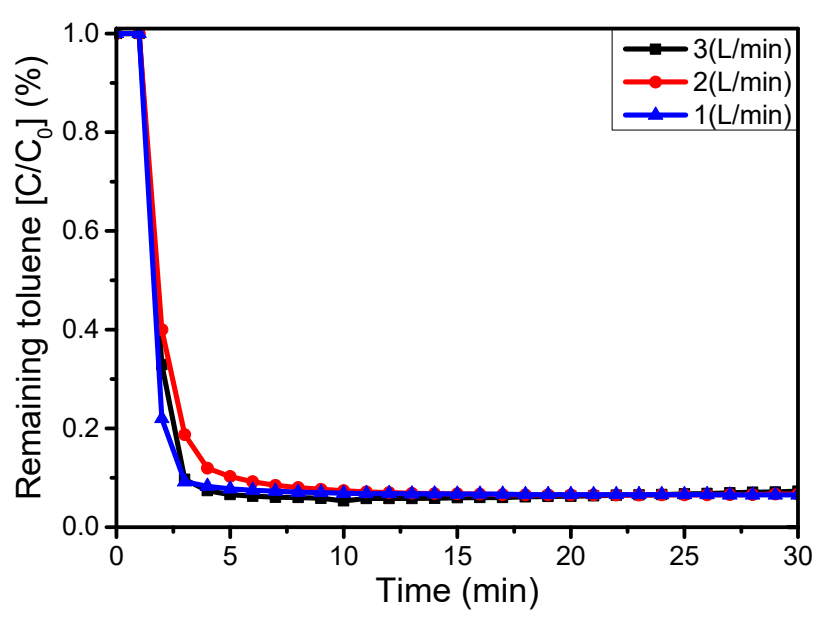

Fig. 14. Effect of different pollutant flow rates on removal efficiency of adsorption module.

radicals $\bullet^{\bullet} \mathrm{O}^{2-}$ and hydroxyl radicals ${ }^{\bullet} \mathrm{OH}$ are generated by the action of the generated electrons and holes transferred to the surface of the photocatalyst. Therefore, the production of superoxide radicals ${ }^{\bullet} \mathrm{O}^{2-}$ and hydroxyl radicals ${ }^{\bullet} \mathrm{OH}$ were increased by increasing the ambient of humidity. So, the humidity is an important parameter in photocatalytic reactions. However, the environmental humidity was decreased the adsorption capacity of activated carbon (Barmeh et al., 2018) because the activated carbon is not only one which adsorbed the pollutants, but the water molecules are also adsorbed. Once the water molecules condensed on the surface of the activated carbon, the adsorption rate is reduced. The photocatalytic commercial module is combined of the photocatalytic module and adsorption module, so the influence of environmental humidity on its parameter worth exploring.

\section{Toluene Removal Rate of Photocatalytic Commercial Modules at Different Humidity}

The results of photocatalytic commercial module test under different environmental humidity are depicted in Fig. 15. It confirmed from the experimental results that the photocatalytic commercial module shows the best removal efficiency was higher than $95 \%$ when the ambient humidity is lower than $4 \mathrm{RH} \%$, the concentration of toluene inside the photocatalytic commercial module was also low and undetected by photoionization detector (PID) after 58 minutes at ambient humidity lower than $4 \mathrm{RH} \%$. The photocatalytic commercial module removal efficiency reached more than $90 \%$ at the ambient humidity lower than 10RH $\%$ and $77.12 \%$ at the ambient humidity of $60 \mathrm{RH} \%$ respectively.

\section{Effect of Different Flow Rate of Contaminant in Photocatalytic Commercial Modules}

The parameter of inlet flow rate controls the contact time of the pollutants, the photocatalyst and the activated carbon. The higher flow rate, the more pollutants can be processed per unit time. The flow rate of pollutant is a crucial parameter in the photocatalytic commercial module. Therefore, this study was testing the efficiency of removing 


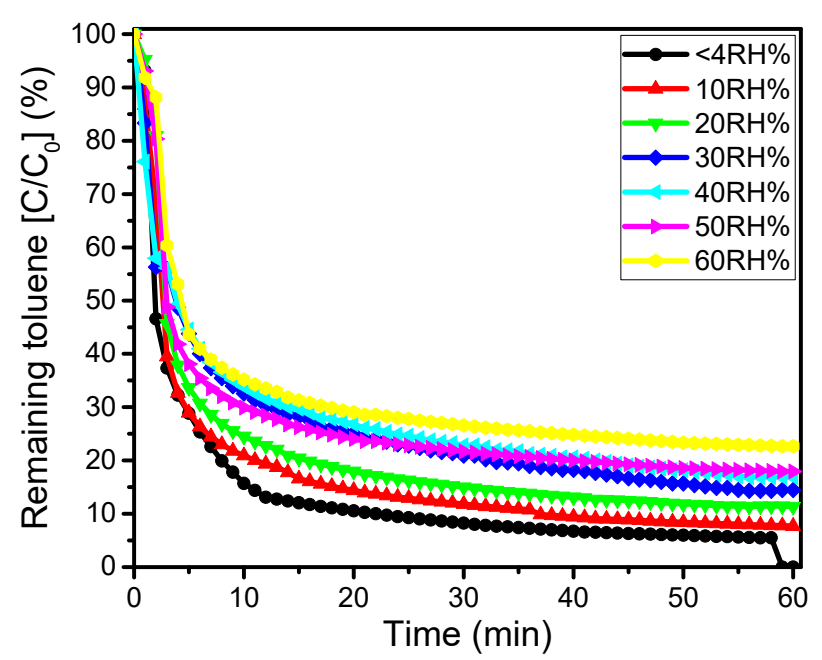

Fig. 15. Toluene removal rate of photocatalytic commercial modules at different humidity.

toluene from photocatalytic commercial modules for different concentrations of pollutant. The effect of photocatalytic commercial modules on the degradation efficiency of toluene under different flow rates is shown in Fig. 16. The experimental results depict that the photocatalytic commercial module is assembled with flow rate less than 3 liters per minute. The best for photocatalytic commercial module has removal efficiency of toluene was achieved higher than $95 \%$. Subsequently, the flow rate of the pollutant was kept using $3 \mathrm{~L} \mathrm{~min}^{-1}$ for further experiments.

\section{Long-acting Test of Photocatalytic Commercial Modules}

The long-term tests showed that the photocatalytic commercial modules can be practically applied to soil vapor extraction (SVE) remediation in the future. The duration of this experimental test was 3 days. The experimental result showed that the photocatalytic commercial module was carried a good stability for the degradation of the pollutants for long time, in the future; the probability of applying photocatalytic commercial modules to SVE remediation equipment can be greatly improved.

The results of the long-term test of the photocatalytic commercial module is shown in Fig. 17, the experimental results showed that the photocatalytic commercial module can remove about $90 \%$ of the pollutants within $22 \mathrm{~min}$. At 58 th $\min$, the concentration of the internal pollutants in the module was lower than 5\%, and finally at the 59th min the concentration of toluene was totally degraded. The internal toluene concentration of the module has been lower than the detection limit of the photoionization detector (PID) equipment and continued until the end of the experiment. Through this experiment, it can be known that the photocatalytic commercial module assembled it can be removed the pollutants for long time of experiment. It was also verified that the feasibility of applying the module to the actual site.

\section{Photocatalytic Commercial Module Actual Site Test}

To test whether the photocatalytic commercial module was assembled in this research can be practically applied to

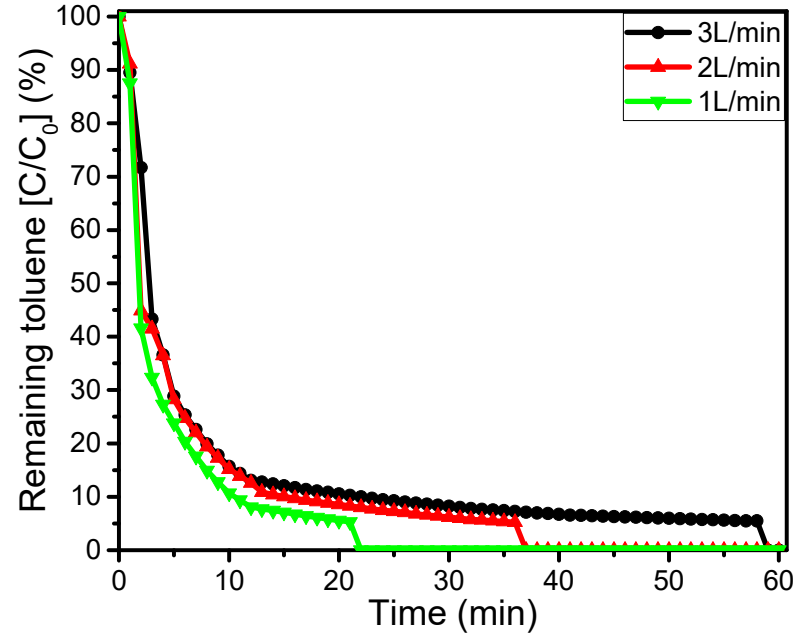

Fig. 16. Comparison of removal efficiency of different flow rate of contaminant in photocatalytic commercial modules.

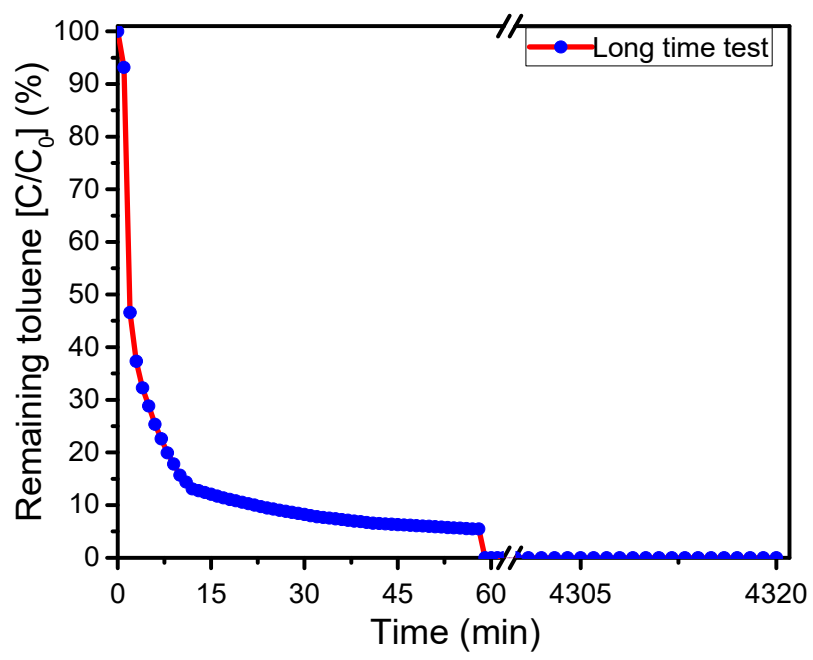

Fig. 17. Long-acting test of photocatalytic commercial modules.

soil vapor extraction (SVE) remediation equipment. The actual site test was carried out at a gas station in northern Taiwan. The test results of the photocatalytic commercial module to the actual site are shown in Fig. 18. The experimental results showed that the removal of the pollutants inside of the photocatalytic module was lower than the limit of the photoionization detector (PID) instrument during the first 15 minutes of the experiment. Therefore, it can be known as the photocatalytic commercial module setup by the research institute can effectively and quickly removed the pollutants in the actual pollution field.

\section{Experiment on Real Site}

The pre-test module in the first step toluene gas was passed through the photoionization detector (PID) to calculate the initial concentration of toluene gas which was $30 \mathrm{ppm}$ at the site after calculating its concentration. In the $2^{\text {nd }}$ step the photocatalytic commercial module was introduced to toluene gas. In this process the toluene gas was connected 


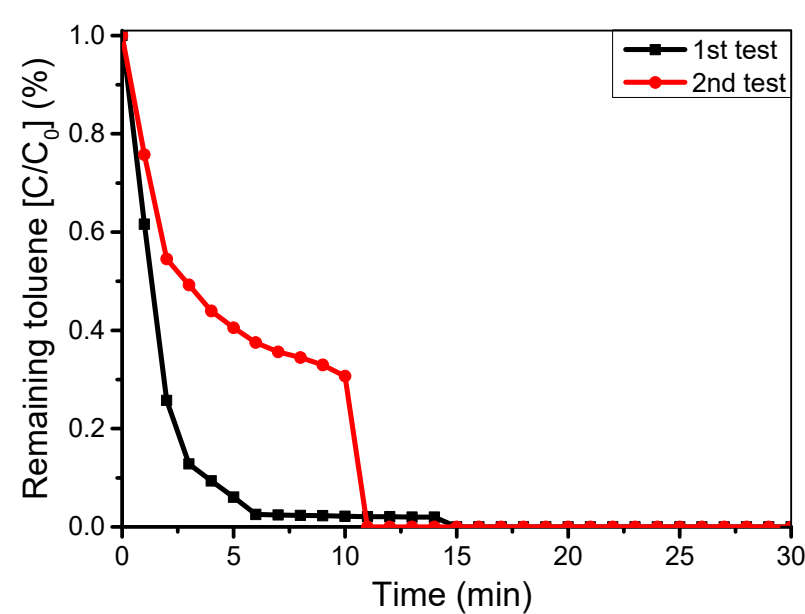

Fig. 18. Photocatalytic commercial module actual site test.

with the photocatalytic module then passed through the adsorption module and then the gas from outlet point was connected with the photoionization detector (PID) to calculate the total degradation of toluene gas.

After passing the Toluene gas through the photocatalytic commercial module it was connected with PID. The real is shown in the Fig. 19, at the first 2 minutes the concentration of Toluene gas was decreased gradually after 2 minutes the degradation was reached at $100 \%$ and remains the same till 30 minutes.

\section{Reaction Equation of Photocatalytic Degradation Mechanism}

The mechanism of the degradation of Toluene is shown in Fig. 20. By which the hydroxyl and superoxide radicals were generated by $\mathrm{La}-\mathrm{TiO}_{2}$ under visible light is described by the following reactions:

$$
\begin{aligned}
& \mathrm{La}-\mathrm{TiO}_{2} \rightarrow \mathrm{e}^{+}+\mathrm{h}^{+} \\
& \mathrm{e}^{-}+\mathrm{O}_{2} \rightarrow \mathrm{O}_{2}^{-} \\
& \mathrm{h}^{+}+\mathrm{H}_{2} \mathrm{O} \rightarrow \mathrm{H}^{+}+\bullet{ }^{\bullet} \mathrm{OH} \\
& 2 \mathrm{~h}^{+}+2 \mathrm{H}_{2} \mathrm{O} \rightarrow 2 \mathrm{H}^{+}+\mathrm{H}_{2} \mathrm{O}_{2} \\
& \mathrm{H}_{2} \mathrm{O}_{2} \rightarrow 2 \bullet \mathrm{OH} \\
& 36^{\bullet} \mathrm{OH}+\mathrm{C}_{7} \mathrm{H}_{8} \rightarrow 7 \mathrm{CO}_{2}+22 \mathrm{H}_{2} \mathrm{O}
\end{aligned}
$$

\section{Toluene Removal from Preview Researchers Compare to Our Study}

Most of the removals of Toluene from preview researchers were realized under UV light because UV light has been showed the best performance than the visible light. but UV method needs more energy and also more dangerous for human being, however in our study we used visible light by using low energy and have a high removal efficiency, additionally visible light is the easier source of light which is available for us, so those comparisons have been showed in the Table 1 that our method could be used wherever for reducing the Toluene gas.

\section{CONCLUSION}

In this study, the photocatalytic commercial module was prepared consisting of photocatalytic module with adsorption

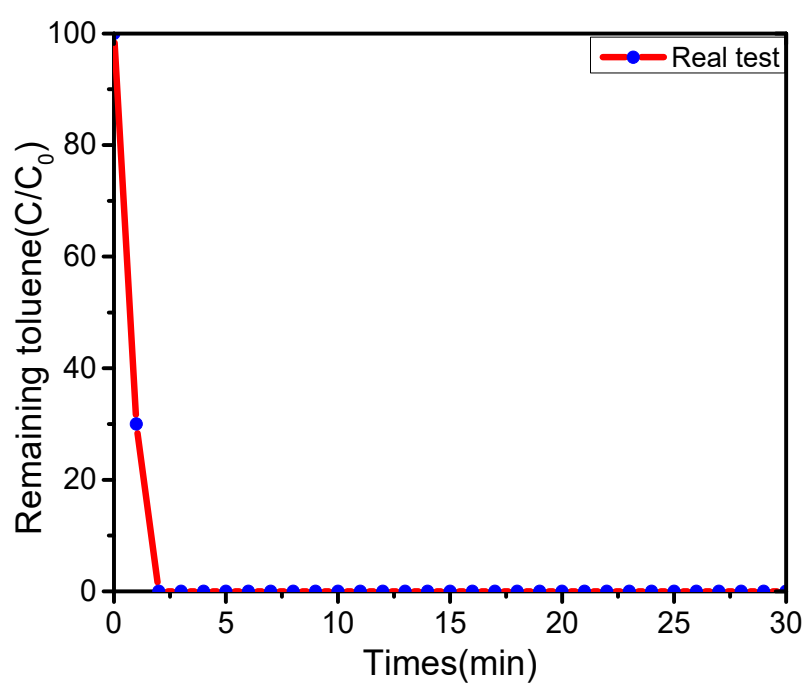

Fig. 19. Experiment on real site.

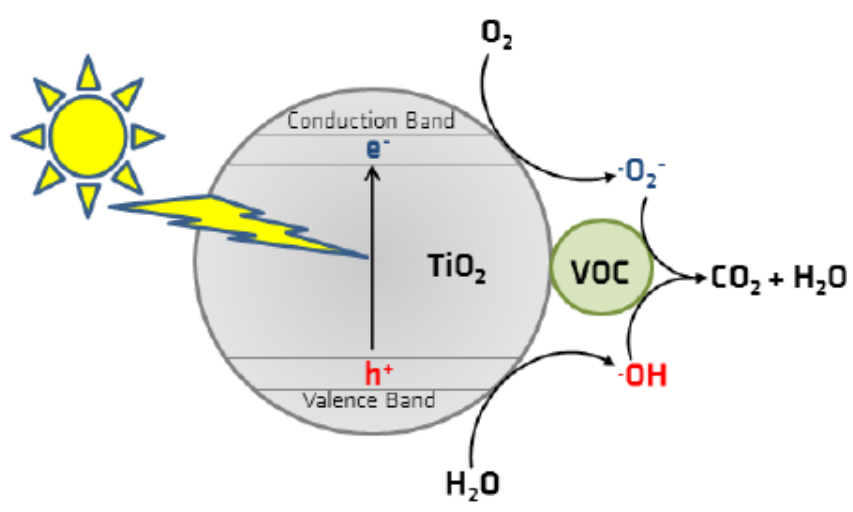

Fig. 20. Photocatalytic degradation mechanism.

module and photocatalitic method under visible light for degradation of soil vapor extraction (SVE), compare and select the best parameters of the photocatalytic commercial module by adjusting various parameters. The X-ray diffraction (XRD), Scanning electron microscopy (SEM) and the diffused reflectance spectroscopy (DRS), showed the synthesis of the catalyst were successfully prepared. After using the optimal parameters of the photocatalytic commercial module completed, the actual pollution site test was carried out with this parameter. The test results were showed that the best parameter of the photocatalytic commercial module arranged in 4 pieces of photocatalytic glass fiber into the photocatalytic module. The adsorption module used 5 layers of carrier and $30 \mathrm{~g}$ of activated carbon in each carrier, and the optimal environmental humidity of the whole module was $<4 \mathrm{RH} \%$. By using the above parameters, the toluene gas can be maintained removal efficiency more than $95 \%$ within 1 hour and the removal efficiency can be stable for more than 72 hours. Therefore, through the results of various experiments, it can be known that the photocatalytic commercial module has a potential to improve the exhaust gas and treatment equipment of the existing soil gas extraction method. 
Table 1. Toluene removal from preview publication.

\begin{tabular}{|c|c|c|c|c|}
\hline Materials & $\begin{array}{l}\text { Concentration } \\
\text { of toluene } \\
\left(\mathrm{mg} \mathrm{L}^{-1}\right)\end{array}$ & $\begin{array}{l}\text { Removal } \\
\text { efficiency } \\
(\%)\end{array}$ & Irradiation sources & References \\
\hline $\mathrm{BiOI} / \mathrm{Bi}_{2} \mathrm{WO}_{6} / \mathrm{ACF}$ & 0.5 & $76.3 \%$ & ultraviolet lamp & Wang et al., 2019 \\
\hline $\mathrm{TiO}_{2} / \mathrm{ZSM}-5$ & 2400 & $70 \%$ & UV lamp & Dinh et al., 2018 \\
\hline $\begin{array}{l}\mathrm{MnO}_{2} \text {-Based Ozone decomposition } \\
\text { catalyst (ODC) }\end{array}$ & 40 & $100 \%$. & UV irradiation & Sekiguchi et al., 2017 \\
\hline ozone catalytic oxidation (OZCO) & 10 & $100 \%$. & UV irradiation & Sekiguchi et al., 2017 \\
\hline $\mathrm{P} 25-\mathrm{TiO}_{2}$ & 1.047 & $40 \%$ & UV irradiation & Binas et al., 2019 \\
\hline $\mathrm{Mn}-\mathrm{TiO}_{2}$ & 1.047 & $20 \%$ & Visible light & Binas et al., 2019 \\
\hline $\begin{array}{l}\text { Corona discharge }+ \text { photoionizer } \\
\text { irradiation }+\mathrm{TiO}_{2}\end{array}$ & 11 & $86 \%$ & UV lamps & Jung et al., 2018 \\
\hline $\mathrm{F}-\mathrm{TiO}_{2} / \mathrm{SiO}_{2}$ & 10 & $91.2 \%$ & Sunlight irradiation & Qiu et al., 2018 \\
\hline TiNbON & 5 & $58 \%$ & Visible light & Zhong et al., 2017 \\
\hline $\mathrm{TiO}_{2} / \mathrm{Mo}-\mathrm{TiO}_{2}$ & 100 & $80 \%$ & UV irradiation & Cui et al., 2017 \\
\hline $\mathrm{AC}-\mathrm{ZnO} / \mathrm{SnO}_{2}$ & 0.075 & $40 \%$ & UV irradiation & Rangkooy et al., 2017 \\
\hline Our method & 15 & $95 \%$ & Visible light & Our study \\
\hline
\end{tabular}

\section{ACKNOWLEDGEMENT}

We want to thank Chung Yuan Christian University (Taiwan) and Faculty of Materials Science and Technology, Environmental Protection Agency (EPA 1082703), Environmental Protection Bureau of Chiayi City 60045, Taiwan and Environmental Protection Administration Executive Yuan, Taipei City 10042, Taiwan for the support of this work.

\section{DSICLAIMER}

The authors declare no competing financial interests.

\section{REFERENCES}

Alvim, D.S., Gatti, L.V., Corrêa, S.M., Chiquetto, J.B., Santos, G.M., de Souza Rossatti, C., Pretto, A., Rozante, J.R., Figueroa, S.N., Pendharkar, J. and Nobre, P. (2018). Determining VOCs reactivity for ozone forming potential in the megacity of São Paulo. Aerosol Air Qual. Res. 18: 2460-2474.

Barmeh, A., Nilforoushan, M.R. and Otroj, S. (2018). Wetting and photocatalytic properties of Ni-doped $\mathrm{TiO}_{2}$ coating on glazed ceramic tiles under visible light. Thin Solid Films 666: 137-142.

Binas, V., Stefanopoulos, V., Kiriakidis, G. and Papagiannakopoulos, P. (2019). Photocatalytic oxidation of gaseous benzene, toluene and xylene under UV and visible irradiation over $\mathrm{Mn}$-doped $\mathrm{TiO}_{2}$ nanoparticles. $J$. Materiomics 5: 56-65.

Cheng, K., Hao, W.W., Yi, P., Zhang, Y. and Zhang, J.Y. (2018). Volatile organic compounds emission from chinese wood furniture coating industry: Activity-based emission factor, speciation profiles, and provincial emission inventory. Aerosol Air Qual. Res. 18: 2813-2825.

Chiou, C.H. and Juang, R.S. (2007). Photocatalytic degradation of phenol in aqueous solutions by Pr-doped $\mathrm{TiO}_{2}$ nanoparticles. J. Hazard. Mater. 149: 1-7.
Cui, M., Pan, S., Tang, Z., Chen, X., Qiao, X. and Xu, Q. (2017). Physiochemical properties of $n-n$ heterostructured $\mathrm{TiO}_{2} / \mathrm{Mo}-\mathrm{TiO}_{2}$ composites and their photocatalytic degradation of gaseous toluene. Chem. Speciation Bioavailability 29: 60-69.

Dinh, V.T., Thu, P.A., An, N.T. and Long, N.Q. (2018). Toluene removal under humid conditions by synergistic adsorption-photocatalysis using nano $\mathrm{TiO}_{2}$ supported on ZSM-5 synthesized from rice-husk without structuredirecting agent. React. Kinet. Mech. Catal. 125: 10391054.

Eshaghi, A. and Moradi, H. (2018). Optical and photocatalytic properties of the Fe-doped $\mathrm{TiO}_{2}$ nanoparticles loaded on the activated carbon. Adv. Powder Technol. 29: 1879-1885.

Feng, H., Xu, H., Feng, H., Gao, Y. and Jin, X. (2019). The sol-gel synthesis and photocatalytic activity of $\mathrm{Gd}-\mathrm{SiO}_{2}$ $\mathrm{TiO}_{2}$ photocatalyst. Chem. Phys. Lett. 733: 136676.

Gao, Q., Si, F., Zhang, S., Fang, Y., Chen, X. and Yang, S. (2019). Hydrogenated F-doped $\mathrm{TiO}_{2}$ for photocatalytic hydrogen evolution and pollutant degradation. Int. J. Hydrogen Energy 44: 8011-8019.

Guerra, F.D., Smith, G., Alexis, F. and Whitehead, D.C. (2017). A survey of VOC emissions from rendering plants. Aerosol Air Qual. Res. 17: 209-217.

Ho, C.C., Kang, F., Chang, G.M., You, S.J. and Wang, Y.F. (2019). Application of recycled lanthanum-doped $\mathrm{TiO}_{2}$ immobilized on commercial air filter for visible-light photocatalytic degradation of acetone and NO. Appl. Surf. Sci. 465: 31-40.

Hoseini, S.N., Pirzaman, A.K., Aroon, M.A. and Pirbazari, A.E. (2017). Photocatalytic degradation of 2,4-dichlorophenol by Co-doped $\mathrm{TiO}_{2}\left(\mathrm{Co} / \mathrm{TiO}_{2}\right)$ nanoparticles and $\mathrm{Co} / \mathrm{TiO}$ containing mixed matrix membranes. J. Water Process Eng. 17: 124-134.

Hu, B., Xu, H., Deng, J., Yi, Z., Chen, J., Xu, L., Hong, Z., Chen, X., Hong, Y.J.A. and Research, A.Q. (2018). Characteristics and source apportionment of volatile organic compounds for different functional zones in a 
coastal city of southeast China. Aerosol Air Qual. Res. 18: 2840-2852.

Hua, X., Wu, Y.J., Zhang, X., Cheng, S., Wang, X., Chu, J., Huang, Q.J.A. and Research, A.Q. (2018). Analysis on ambient volatile organic compounds and their human gene targets. Aerosol Air Qual. Res. 18: 2654-2665.

Huang, Y., Cao, J.J., Kang, F., You, S.J., Chang, C.W. and Wang, Y.F. (2017). High selectivity of visible-light-driven La-Doped $\mathrm{TiO}_{2}$ photocatalysts for no removal. Aerosol Air Qual. Res. 17: 2555-2565.

Irie, H., Watanabe, Y. and Hashimoto, K. (2003). NitrogenConcentration Dependence on Photocatalytic Activity of $\mathrm{TiO}_{2}-\mathrm{xNx}$ Powders. J. Phys. Chem. B 107: 5483-5486.

Ishikawa, N., Sekiguchi, K.J.A. and Research, A.Q. (2018). Measurements of the size and composition of volatile particles generated from a heated tobacco product with aerosol fixation agents. Aerosol Air Qual. Res. 18: 25382549.

Jung, S., Fang, J., Chadha, T.S. and Biswas, P. (2018). Atmospheric pressure plasma corona enhanced by photoionizer for degradation of VOCs. J. Phys. D: Appl. Phys. 51: 445206 .

Juuti, P., Nikka, M., Gunell, M., Eerola, E., Saarinen, J.J., Omori, Y., Seto, T., Mäkelä, J.M.J.A. and Research, A.Q. (2019). Fabrication of fiber filters with antibacterial properties for VOC and particle removal. Aerosol Air Qual. Res. 19: 1892-1899.

Kawar, K.H. and Underhill, D.W. (1999). Effect of relative humidity on the adsorption of selected water-miscible organic vapors by activated carbon. Am. Ind. Hyg. Assoc. J. 60: 730-736.

Lerner, J.C., Sanchez, E., Sambeth, J. and Porta, A. (2012). Characterization and health risk assessment of VOCs in occupational environments in Buenos Aires, Argentina. Atmos. Environ. 55: 440-447.

Li, J. and Biswas, P. (2017). Optical characterization studies of a low-cost particle sensor. Aerosol Air Qual. Res. 17: 1691-1704.

Matos, J., Ocares-Riquelme, J., Poon, P.S., Montaña, R., García, X., Campos, K., Hernández-Garrido, J.C. and Titirici, M.M. (2019). C-doped anatase $\mathrm{TiO}_{2}$ : Adsorption kinetics and photocatalytic degradation of methylene blue and phenol, and correlations with DFT estimations. $J$. Colloid Interface Sci. 547: 14-29.

Ou-Yang, C.F., Chang, C.C., Wang, J.L., Shimada, K., Hatakeyama, S., Kato, S., Chiu, J.Y., Sheu, G.R. and Lin, N.H. (2017). Characteristics of summertime volatile organic compounds in the lower free troposphere: Background measurements at Mt. Fuji. Aerosol Air Qual. Res. 17: 3037-3051.

Qiu, L., Wang, Y., Li, H., Cao, G., Ouyang, F. and Zhu, R. (2018). Photocatalytic oxidation of toluene on fluorine doped $\mathrm{TiO}_{2} / \mathrm{SiO}_{2}$ catalyst under simulant sunlight in a flat reactor. Catalysts 8: 596.

Qiu, P., Sun, X., Lai, Y., Gao, P., Chen, C. and Ge, L. (2019). $\mathrm{N}$-doped $\mathrm{TiO}_{2} @ \mathrm{TiO}_{2}$ visible light active film with stable and efficient photocathodic protection performance. $J$. Electroanal. Chem. 844: 91-98.

Rangkooy, H.A., Tanha, F., Jaafarzadeh, N. and
Mohammadbeigi, A. (2017). The influence of $\mathrm{ZnO}-\mathrm{SnO}_{2}$ nanoparticles and activated carbon on the photocatalytic degradation of toluene using continuous flow mode. Med. Gas Res. 7: 260.

Rathfelder, K., Lang, J. and Abriola, L. (1995). Soil vapor extraction and bioventing: Applications, limitations, and future research directions. Rev. Geophys. 33: 1067-1081.

Sekiguchi, K., Kurita, Y., Sankoda, K., Namiki, N., Yasui, F. and Tamura, H. (2017). Ozone catalytic oxidation of gaseous toluene over $\mathrm{MnO}_{2}$-based ozone decomposition catalysts immobilized on a nonwoven fabric. Aerosol Air Qual. Res. 17: 2110-2118.

Shafei, A. and Sheibani, S. (2019). Visible light photocatalytic activity of $\mathrm{Cu}$ doped $\mathrm{TiO}_{2}-\mathrm{CNT}$ nanocomposite powder prepared by sol-gel method. Mater. Res. Bull. 110: 198206.

Shao, X., Pan, F., Zheng, L., Zhang, R. and Zhang, W.Y. (2018). Nd-doped $\mathrm{TiO}_{2}-\mathrm{C}$ hybrid aerogels and their photocatalytic properties. New Carbon Mater. 33: 116124.

Singh, K., Harish, S., Archana, J., Navaneethan, M., Shimomura, M. and Hayakawa, Y. (2019). Investigation of Gd-doped mesoporous $\mathrm{TiO}_{2}$ spheres for environmental remediation and energy applications. Appl. Surf. Sci. 489: 883-892.

Tbessi, I., Benito, M., Molins, E., LIorca, J., Touati, A., Sayadi, S. and Najjar, W. (2019). Effect of Ce and Mn codoping on photocatalytic performance of sol-gel $\mathrm{TiO}_{2}$. Solid State Sci. 88: 20-28.

Thiruppathi, M., Kumar, P.S., Devendran, P., Ramalingan, C., Swaminathan, M. and Nagarajan, E. (2018). Ce@ $\mathrm{TiO}_{2}$ nanocomposites: An efficient, stable and affordable photocatalyst for the photodegradation of diclofenac sodium. J. Alloys Compd. 735: 728-734.

Wang, C.H., Hua, H.C., Lin, W.C., Hsieh, H.C. and Wang, J.L. (2018). A new gas chromatography method for continuous monitoring of non-methane hydrocarbons as an analogy of volatile organic compounds in flue gas. Aerosol Air Qual. Res. 18: 2913-2921.

Wang, Y., Jiang, S., Liu, F., Zhao, C., Zhao, D. and Li, X. (2019). Study on preparation and toluene removal of BiOI/Bi2WO6/ACF photocatalyst. Appl. Surf. Sci. 488: 161-169.

Widiana, D.R., You, S.J., Yang, H.H., Tsai, J.H. and Wang, Y.F. (2017). Source apportionment of air pollution and characteristics of volatile organic compounds in a municipal wastewater treatment plant, north Taiwan. Aerosol Air Qual. Res. 17: 2878-2890.

Yajun, W., Kecheng, L. and Changgen, F. (2011). Photocatalytic degradation of methyl orange by polyoxometalates supported on yttrium-doped $\mathrm{TiO}_{2}$. J. Rare Earths 29: 866-871.

Yu, Y., Liu, L., Yang, C., Kang, W., Yan, Z., Zhu, Y., Wang, J. and Zhang, H. (2019). Removal kinetics of petroleum hydrocarbons from low-permeable soil by sand mixing and thermal enhancement of soil vapor extraction. Chemosphere 236: 124319.

Zhong, L., Brancho, J.J., Batterman, S., Bartlett, B.M. and Godwin, C. (2017). Experimental and modeling study of 
visible light responsive photocatalytic oxidation (PCO) materials for toluene degradation. Appl. Catal., B 216: $122-132$.
Received for review, October 6, 2019

Revised, October 27, 2019

Accepted, November 9, 2019 